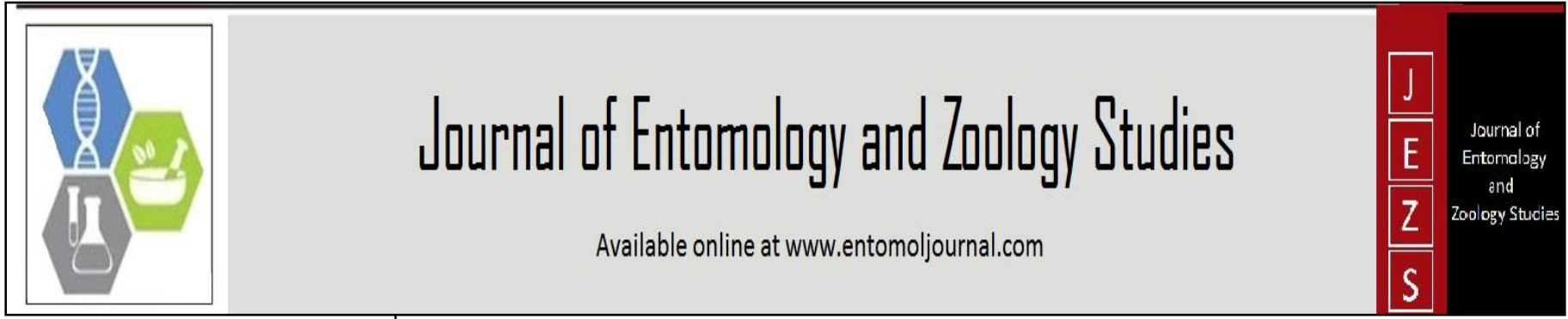

E-ISSN: 2320-7078

P-ISSN: 2349-6800

www.entomoljournal.com JEZS 2020; 8(4): 929-935 (C) $2020 \mathrm{JEZS}$

Received: 10-05-2020

Accepted: 12-06-2020

\section{Chaitra S}

Department of Studies in Sericulture, University of Mysore, Manas Agangothri, Mysore, Karnataka, India

\section{Prashanth J}

Department of Studies in

Sericulture, University of

Mysore, Manas Agangothri,

Mysore, Karnataka, India

Jagadeeshkumar TS

Department of Studies in Sericulture, University of Mysore, Manas Agangothri, Mysore, Karnataka, India

Corresponding Author: Prashanth J

Department of Studies in Sericulture, University of Mysore, Manas Agangothri, Mysore, Karnataka, India

\section{Empirical analysis of uric acid in Malpighian tubules and dry excrements and economic traits of the silkworm hybrids}

\author{
Chaitra S, Prashanth J and Jagadeeshkumar TS
}

DOI: https://doi.org/10.22271/j.ento.2020.v8.i4o.7237

\section{Abstract}

In the present study the amount of nitrogenous uric acid is found to be determined both in malpighian tubules and dry litter during fifth instar silkworm larvae. The PM X CSR 2 multi-bi hybrid and $\mathrm{FC}_{2} \mathrm{X} \mathrm{FC}_{1}$ bivoltine double hybrid silkworm revealed positive response and consistent increase in the level of production of uric acid. The pattern of formation of uric acid in malpighian tubules of both the hybrids exhibits consistent level of increase in all the days of fifth instar; however, the quantum of uric acid is relatively more on the last two days of fifth instar silkworm larvae. The level of changes in uric acid content is comparatively higher than the Malpighian tubules in all the days of V instar silkworm of both the hybrids. The expression and manifestation of both the quantitative and qualitative traits of PM X $\mathrm{CSR}_{2}$ and $\mathrm{FC}_{2} \mathrm{X} \mathrm{FC}_{1}$ were recorded. The cocoon characters of $\mathrm{FC}_{2} \mathrm{X} \mathrm{FC}_{1}$ hybrid showed better in performance in the expression and manifestation compare to PM X CSR 2 hybrid in cocoon weight, shell weight and shell ratio pre-monsoon. The filament length and filament weight are the qualitative parameters also reflected on par with the cocoon characters. The thickness of the filament is predetermined and reflected the quality of the silk. In $\mathrm{FC}_{2} \mathrm{X} \mathrm{FC}$ the denier is lesser than the PM X CSR 2 which shows the denier is almost doubled. Finally, the quantum of cocoons required to produce one $\mathrm{kg}$ of raw silk is of almost $5.36 \mathrm{~kg}$ whereas, the PM X CSR 2 showed $8.28 \mathrm{~kg}$ for the production of one $\mathrm{kg}$ of raw silk. In the present empirical analysis in relation to the uric acid content in dry excrement and malpighian tubules during fifth instar are carried out to understand the day to day changes in the chief nitrogenous waste product of the silkworm, Bombyx mori L.

Keywords: Silkworm hybrids, uric acid, malpighian tubules, dry excrements and economic traits

\section{Introduction}

Excretion is the process of removal of physiologically, metabolically undesirable components from the body system in order to ensure the active cellular functions of the organism and tend to play an important role for the balance of nitrogen in the body. The nitrogenous products in most of insects are eliminated from the haemolymph through an active cellular function of the malpighian tubules in the form of litter. Most of the terrestrial insects, water conservation is the essential to exhibit the cellar respiration and the water loss by excretion must be reduced to a minimum level. Hence it is necessary to produce a less toxic substance namely uric acid than the ammonia so that, less water is required for its safe elimination. Ammonia is the primary end product of nitrogen metabolism, but it is highly toxic except an extreme dilution. For most of terrestrial insects, water conservation is essential and loss by excretion must be reduced to a minimum level. Hence it is necessary to produce a less toxic substance than ammonia so that less water is required for its safe elimination of uric acid, most of the terrestrial insects excreted out about $80-90 \%$ of the waste nitrogen in the form of uric acid. Urea is commonly present and relatively small amount and it represents less than $10 \%$ of the nitrogen excreted. Nitrogenous waste materials are the end products of them metabolic reactions. Ammonia, urea and uric acid are the major nitrogenous wastes excreted. These waste materials must be removed from the body, if these nitrogen materials are allowed to accumulate in the body itself may become toxic. In view of the significance of various nitrogen products in various metabolic cycles the study was carried out to demonstrate the day to day changes in nitrogen waste products in excrements and malpighian tubules of the silkworm larva, the nitrogenous waste products of the metabolism are mainly excreted as urine together with faecal matter. The excretory pattern depends upon a number of environmental factors such as temperature and humidity ${ }^{[1,8]}$. 
The excretion of nitrogenous waste products has beens tudied in a number of insects $[24,15,7]$. Uric acid contains comparatively less hydrogen than any other nitrogenous compound excreted by animals and it is therefore well adapted for conservation ${ }^{[25]}$. Urea is present in small quantities in insects. The excretion in terrestrial insects, its energetics and functional principles have also been worked out ${ }^{[9]}$.

\section{Materials and methods}

The present experimental analysis was carried out in the department of studies in Sericulture Science, University of Mysore. The popular hybrids of the silkworm hybrids namely, $\mathrm{PM} \mathrm{XCSR}_{2}$ and $\mathrm{FC}_{2} \mathrm{X} \mathrm{FC}_{1}$ were used for the present investigation. The eggs were obtained from cold storage CSR\&TI, Mysore and incubated followed silkworm rearing conducted as per standard method ${ }^{[16]}$. On the $7^{\text {th }}$ day of mounting, the hardly and tough cocoons were harvested and subjected for the evaluation of economic characters namely, cocoon weight, shell weight, shell ratio, filament length, filament weight, denier and renditta were recorded and subjected for statistical analysis.

Maintenance of silkworm hybrids: Two disease free layings (DFLs) of the two hybrids namely, PM X CSR 2 and $\mathrm{FC}_{2} \mathrm{X}$ $\mathrm{FC}_{1}$ about 450-500 eggs were obtained from CSR\&TI Mysore. The eggs were incubated at $25 \pm 1^{\circ} \mathrm{C}$ temperature and $80-85 \%$ relative humidity for about $10-12$ days until hatching. Wooden trays of $90 \times 70 \times 10 \mathrm{~cm}$ size were washed with water, dried and disinfected with $2 \%$ formalin solution and covered with paraffin paper of the same size. The layings were black boxed at blue egg stage in order to obtain a uniform hatching and the hatched larvae on the $10^{\text {th }}$ day were brushed into labelled wooden trays. The silkworm larvae were reared under standard rearing conditions on two feeding schedules [16]. Mulberry leaf of V1 variety were obtained from the garden of sericulture department and selected leaves chopped into suitable size according to the stage were fed to the silkworm. The silkworm beds were cleaned after second moult and thereafter every day. The entire batches silkworms were reared on normal leaf without any treatment till the completion of $5^{\mathrm{h}}$ instar till the day of spinning. The ripened worms were allowed to spin the cocoons on bamboo mountages. The cocoons were harvested on the $7^{\text {th }}$ day harvested cocoons were subjected for the determination of economic traits like cocoon weight, shell weight, shell ratio, length of cocoon filament, and weight of silk reeled, denier and renditta were recorded and subjected for the statistical analysis. Uric acid is determined by standard method the popular silkworm hybrids, namely, $\mathrm{PM} \mathrm{X} \mathrm{CSR}_{2}$ and $\mathrm{FC}_{2} \mathrm{X}$ $\mathrm{FC}_{1}$ were used for the present investigation ${ }^{[4,14]}$. The first day of the $\mathrm{V}$ instar healthy silkworm larvae till the day of spinning, the dry excrement and malpighian tubules were collected in the morning from bed of the silkworm hybrids with regular interval of $24 \mathrm{~h}$ daily The active malpighian tubules were collected after the dissection of the silkworm and kept in the deep freezer at $-20^{\circ} \mathrm{c}$ and the dry excrement (litter) of the silkworm kept in oven for drying and powdered with the help of the mortar and pestle and utilized for the comparative experimental analysis.

Preparation of reagents: $0.66 \mathrm{~N}$ Sulphuric acid: Add $200 \mathrm{ml}$ of distilled water carefully to $6.6 \mathrm{ml}$ of concentrated Sulphuric acid. $10 \%$ Sodium tungstate: $20 \mathrm{~g}$ of Sodium tungstate is dissolved in $200 \mathrm{ml}$ of distilled water. $14 \%$ Sodium Carbonate: Dissolve $28 \mathrm{~g}$ of anhydrous Sodium Carbonate in $200 \mathrm{ml}$ distilled water. Uric acid reagent: Take $12.5 \mathrm{~g}$ of Sodium tungstate and $2.5 \mathrm{~g}$ of anhydrous disodium orthophosphate in conical flask. Add $37.50 \mathrm{ml}$ of distilled water warm to bring into the solution. In another flask gradually add $3.12 \mathrm{ml}$ of concentrated $\mathrm{H}_{2} \mathrm{SO}_{4}$ to $12.5 \mathrm{ml}$ of distilled water, cooled. And diluted sulphuric acid to the tungstate phosphate solution and refluxed the solutions for one-hour cool and diluted to make up $125 \mathrm{ml}$ of distilled water. Uric acid Standard: $50 \mathrm{mg}$ of uric acid and $30 \mathrm{mg}$ of lithium carbonate and then added $50 \mathrm{ml}$ of distilled water subjected for $1 \mathrm{~h}$ at $60^{\circ} \mathrm{c}$. From this, $1 \mathrm{ml}$ of stock solution is taken and diluted up to $10 \mathrm{ml}$ with distilled water.

Estimation of uric acid: 100mg of dry excrement (powder) of malpighian tubules is taken for that add $10 \mathrm{ml}$ of petroleum ether and $10 \mathrm{ml}$ of acetone removed the pigment and collected the residue for that add $1 \mathrm{ml}$ of $0.66 \mathrm{~N} \mathrm{H}_{2} \mathrm{SO}_{4}$ and $1 \mathrm{ml}$ of sodium tungstate allowed to stand for 10 minutes and collected the supernatant after filtration. For blank add $2 \mathrm{ml}$ of distilled water, for standard $2 \mathrm{ml}$ of standard and for samples $2 \mathrm{ml}$ of sample then add $1 \mathrm{ml}$ of $14 \%$ sodium carbonate and $1 \mathrm{ml}$ of uric acid reagent allowed to stand for 15 minutes then OD is taken at $680 \mathrm{~nm}$.

\section{Analysis of economic traits}

1. Cocoon weight (g): This is the average weight in gram of cocoons weighing random sample of 10 cocoons.

2. Shell weight (g): This determines the quantity of the silk available from the cocoon shell after removal of pupae from the cocoons and individual shell weight was calculated using the formula.

Shell weight $=\frac{\text { Weight of shell }}{\text { Cocoon weight }}$

3. Shell Ratio (\%): The cocoon shell percentage was determined by dividing the cocoon shell weight. It is expressed in percentage.

Shell ratio $=\frac{\text { Weight of cocoon shell }(\mathrm{g})}{\text { Weight of } \operatorname{cocoon}(\mathrm{g})} \times 100$

4. Filament Length: Ten cocoons were randomly selected and were reeled to find out the filament length of the cocoon using epprouvette and were determined by adopting the formula:

\section{Length of the filament $\times 1.125$}

5. Denier: This denotes the thickness of the filament, 9000 meters of the silk filament weighing $1 \mathrm{~g}$ is considered as 1 denier. It is calculated using following formula:

Denier $=\frac{\text { Weight of the filament }}{\text { Length of the filament }} \times 9000$

\section{Renditta}

This is a measure of actual silk available from the cocoons. The renditta was expressed as the quantity of cocoons required to get a $\mathrm{kg}$ of raw silk: 
Renditta $=\frac{\text { Cocoon weight }(\mathrm{g})}{\text { Raw silk weight }(\mathrm{g})}$

\section{Results and discussion}

An approach has been made in the present investigation relation to understand the changes in the uric acid content in malpighian tubules and dry excrement of the PM X CSR 2 and $\mathrm{FC}_{2} \mathrm{X} \mathrm{FC}_{1}$ during fifth instar silkworm. Uric acid is the nitrogenous metabolic end product synthesized and released in the form of litter after the metabolic events. In most of the terrestrial insects, silkworm is not an exception and it belongs to group urecotilic organisms. Malpighian tubules are the chief excretory organ of the silkworm opens from right and left side at the junction between the small intestine and the colon. This junction appears has well as a sac like structure called urinary vesicles from the vesicles on each side arises a common duct which bifurcate one of the branches and arises the ducts and proceeds anteriorly along with the midgut surface and tend to bend and turn in the posterior direction. The malpighian tubules are rich with the lactoflavin are present in the lumen of the cells in the form of crystals. Chiefly two types of crystals such as, oxalic acid and uric acid. Uric acid appears to be increased during the day to day changes accordingly with progressive development and the growth rate of the fifth instar silkworm larvae. The silkworm hybrids namely, PM X CSR 2 and $\mathrm{FC}_{2} \mathrm{X} \mathrm{FC} \mathrm{FC}_{1}$ were used for the experimental analysis of the uric acid content in the malpighian tubules and the dry excrement. The malpighian tubules in which the uric acid content analysed and found the consistent level of uric acid is increased in the everyday of malpighian tubules till the day of commencement of the spinning period. From the day one of fifth instar up to sixth day. The quantum of level of the synthesis of uric acid is almost $2.34 \%$ on sixth day, on second day $(0.45 \% 0)$, on third day [0.55\%], on fourth day [0.73\%], on fifth day [2.11\%], on sixth day maximum of $2.34 \%$ were noticed as day to day changes. It is reflected that the quantum of food consumption is increased has larval growth increase. As a result, the nitrogen rich protein sources derived from the coarse mulberry leaves and utilized as much as energy source required in order to ensure cellular metabolic events in turns helps for the release of free amino acids in the haemolymph followed by the maximum utilization for the conversion of silk protein synthesis. Subsequently the excess of nitrogen is absorbed by the lumen of the cells in malpighian tubules and excreted out an undesirable compound in the form of litter. The level of uric acid content in the malpighian tubules is proportionately on par with food consumption and the larval growth rate during fifth instar in the $\mathrm{PM} \mathrm{X} \mathrm{CSR} 2$, hybrid. The pattern of synthesis of uric acid content in the malpighian tubules is almost similar in trend even in $\mathrm{FC}_{2} \mathrm{X} \mathrm{FC}$. The percent change in the $\mathrm{FC}_{2} \mathrm{X} \mathrm{FC}_{1}$ on second day [0.09\%], on third day $[0.18 \%]$, on fourth day $[0.82 \%]$, on fifth day $[1.00 \%]$, on sixth day [1.09\%], on last and seventh day maximum of $1.18 \%$ change were noticed in $\mathrm{FC}_{2} \mathrm{X} \quad \mathrm{FC}_{1}$ hybrid.

The quantum of rate of synthesis of uric acid on fourth day onwards till the day of spinning period exhibits propionately higher and depicts in relation to food consumption and utilization relatively more can act upon the mobilization of the energy for the cellular activity. Similarly, the experimental analysis of uric acid content in the silkworm dry litter also showed a consistent day to day increase in the observation from day one till the day of spinning. It is noteworthy to observe that a significant change on fourth, fifth, sixth day in $\mathrm{PM} \mathrm{X} \mathrm{CSR} 2$. The levels of percent change on second day [3.72\%], on third day [6.06], on fourth day [12.09\%], on fifth day $[14.06 \%]$, on sixth day [15.53\%], were recorded in the present investigation. However, the silkworm hybrids namely, $\mathrm{FC}_{2} \mathrm{X} \mathrm{FC}_{1}$ showed a changes in the uric acid content of dry excrement during fifth instar relatively an increase in the order extended larval period and a food consumption during fifth instar. The percent change on second day [1.23\%], on third day [2.00\%], on fourth day [5.96\%], on fifth day [7.45\%], on sixth day [7.73\%], on seventh day almost 13.50 are found to be noticed and highest compare to the level of uric acid from first day to sixth day in the dry excrement of fifth instar larvae. The uric acid content in the dry excrement of $\mathrm{FC}_{2} \mathrm{X} \mathrm{FC}_{1}$ showed a relatively more when compare to uric acid content and dry excrement of PM X CSR2 in day to day observations. The unique observations in the experimental investigation in both the hybrids namely, $\mathrm{PM} \mathrm{X} \mathrm{CSR} 2$ and $\mathrm{FC}_{2}$ $\mathrm{X} \mathrm{FC}$ the dry excrement showed the maximum uric acid content and proportionately higher when compare to uric acid content of the malpighian tubules.

Uric acid is the principal nitrogenous excretory product of terrestrial insects. Most of the nitrogenous waste excreted by the insects at any stage of the development is represented by this metabolite. Uric acid or allantoic is a major larval excretory product of several species of Lepidoptera ${ }^{[17]}$. Large number of lepidopteron species shown to have uric acid as the predominant excretory product of both larval and pupal stages [5]. Uric acid is the primary excretory product of the nitrogen and purine metabolism in $B$. mori. It has to be excreted out as and when it is formed, so that a lower level is maintained in the haemolymph which will not in any way affect the normal growth of the larvae. Uric acids have many vital functions rather than being only an excretory product or induce pigmentation. Uric acid can possibly serve as an amino acid pre-precursor ${ }^{[13]}$. It also can act in biological system as a powerful antioxidant and it serves a protective function not only against predators in mimicry system, but also against oxidative stress generated by the phototoxic allele chemicals [23]. Larvae of antlion, excreted smaller quantities of nitrogenous excretory products during starvation than during periods of food abundance and suggested that quality and quantity of diet have a major impact upon the concentrations of uric acid in many insects ${ }^{[5,11]}$. In view of the significance of various nitrogen products in various metabolic cycles. In the silkworm larva, the nitrogenous waste products of metabolism are mainly excreted as urine, together with faecal pellets. The excretory pattern depends upon a number of environmental factors such as temperature and humidity ${ }^{[1,8]}$. The excretory pattern of silkworm larvae on exposure to F2 alpha increased the nitrogenous end products ${ }^{[2]}$. Similarly, larvae feeding with trace elements like cobalt increased the pattern of excretion ${ }^{[18]}$. Excretion forms an important factor for the balance of the nitrogen in the body. The excretion of nitrogenous waste products has been studied in a number of insects [24, 15, 7]. Uric acid contains comparatively less hydrogen than any other nitrogenous compound excreted by animals and it is therefore well adapted for conservation ${ }^{[25]}$. Urea is present in small quantities in insects. The excretion in insects, its energetics and functional principles have also been worked out ${ }^{[9]}$. As there is limited information regarding tasar silkworm excretion, an attempt has been made here to compare the excretory pattern in the pellets of outdoor and indoor reared Andhra local tasar silkworms. The excretory 
products, urea and uric acid contents were found to be at a higher level in the silkworm reared under indoor conditions. Instar-wise, in the fourth instar, ammonia and glutamine content were found at a significantly higher level in the indoor worms as compared to the fifth instar while urea and uric acid content are in the reverse order showing higher content in the fifth instar ${ }^{[19]}$. Of the four nitrogenous products, urea in the fifth instar larvae of indoor rearing is found to be maximum. The fourth instar silkworm had more significant difference between the outdoor and indoor worms. It is well known that the terrestrial insects generally excrete uric acid exhibiting uricotelism ${ }^{[6,15]}$. It is also reported that excretion in insects is variable depending upon habitat ${ }^{[26]}$. The higher level of nitrogenous products during fourth instar indicates higher breakdown of the end products which is correlated with high growth rate, during fifth instar, formation of nitrogenous end products lesser due to depleted growth rate while silk synthesis in the glands takes place at a rapid pace. In both the instars an increase of the excretory material in the indoor worms has been observed.

A few workers have been attempted to demonstrate the excretory products of genus Antheraea ${ }^{[12,10]}$. These studies reveal that there is lability within the life history of the individual where the ratio of major three end products may fluctuate enormously from day to day and the major end product is invariably the uric acid. The present studies also showed relatively constant higher content of uric acid in the indoor reared silk worms of both fourth and fifth instars. The tasar silk industry has contributed substantially towards the economic development of tribes in India. The unscientific exploitation of Antheraea species, its multiplication and rearing on forest plants for cocoon production resulted in heterogeneity. The distribution, phenotypic and behavioural expression of various eoctypes of Antheraea species existing in different parts of India are based on environment- food plant, forest type, soil type and altitude of the area. Some of the eco-races of Antheraea mylitta viz., Raily, Modal, Bhandara, Sukinda, Daba, Andhra local are being maintained in different locations in forest area. However, it lacked scientific approach of conservation of species in natural condition. Genetic identity of these species through biochemical studies and their regular monitoring in every generation gives precise information about the homozygosity in the population of these insect species. As many ecotypes of tasar silkworm have been lost due to inbreeding, adverse climate and sudden outbreak of diseases, an establishment of 'breeding parks' has been suggested to overcome the problem [22].

The present studies have successfully paved the way towards a scientific approach for the conservation of the tasar silkworm, Antheraea mylitta (Andhra local eco race). The methodology of total indoor rearing followed by bio-chemical studies of various substrates like trehalose, glucose, proteins, lipids, lactic acid and pyruvic acid [20,21] and DNA fingerprinting of ecoraces of Antheraea mylitta- Andhra local and Daba TV have contributed to the research field of tasar culture ${ }^{[20]}$. The present studies on amino acids, urea and uric acid are based on nitrogen metabolism and amino acids, the constituents of the silk proteins -fibroin and sericin. It is said that, environment is helpful for economic development; but economic development is harmful to environment. In the present studies, as a measure of conservation of Antheraea mylitta, Andhra local eco race, an attempt towards total indoor rearing has been made in order to overcome a few environmental hazards and disease outbreak.

Table 1: Changes in the uric acid content in the malpighian tubules of the PM X CSR 2 during fifth instar (Each value is mean of the three separate observations)

\begin{tabular}{|c|c|c|}
\hline Days & mg of uric acid/g & \% change \\
\hline 1 & $10.84 \pm 0.001$ & - \\
\hline 2 & $10.89 \pm 0.003$ & $0.459 \mathrm{NS}$ \\
\hline 3 & $10.90 \pm 0.002$ & $0.550 \mathrm{NS}$ \\
\hline 4 & $10.92 \pm 0.002$ & $0.730 \mathrm{NS}$ \\
\hline 5 & $11.07 \pm 0.005$ & $2.077 \mathrm{NS}$ \\
\hline 6 & $11.10 \pm 0.001$ & $2.342 \mathrm{NS}$ \\
\hline
\end{tabular}

$\mathrm{NS}=$ Non significant

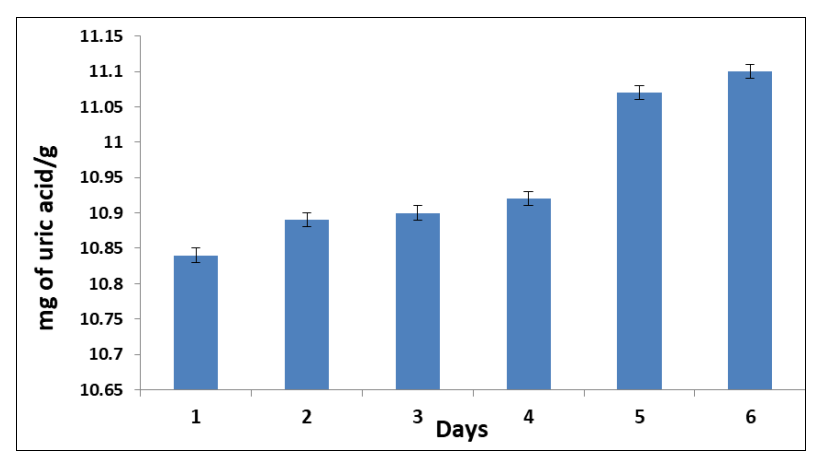

Fig 1: Changes in the uric acid content of malpighian tubules of PM $\mathrm{X} \mathrm{CSR} 2$ during fifth instar

Table 2: Changes in the uric acid content in the malpighian tubules of $\mathrm{FC}_{2} \mathrm{X} \mathrm{FC}$ during fifth instar (Each value is mean of the three separate observations)

\begin{tabular}{|c|c|c|}
\hline Days & mg of uric acid/g & Percentage change \\
\hline 1 & $10.84 \pm 0.001$ & $-0.092 \mathrm{NS}$ \\
\hline 2 & $10.85 \pm 0.002$ & $0.184 \mathrm{NS}$ \\
\hline 3 & $10.86 \pm 0.003$ & $0.823 \mathrm{NS}$ \\
\hline 4 & $10.93 \pm 0.001$ & $1.004 \mathrm{NS}$ \\
\hline 5 & $10.95 \pm 0.003$ & $1.094 \mathrm{NS}$ \\
\hline 6 & $10.96 \pm 0.003$ & $1.185 \mathrm{NS}$ \\
\hline 7 & $10.97 \pm 0.002$ & \\
\hline
\end{tabular}

NS = Non significant

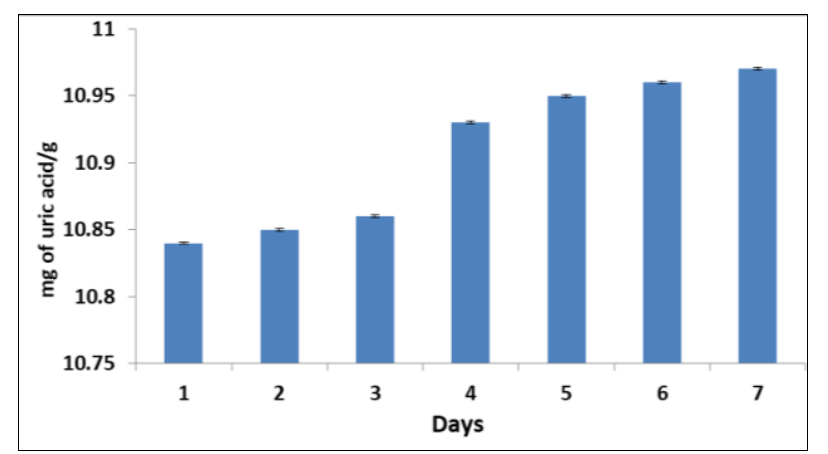

Fig 2: Changes in the uric acid content of malpighian tubules of $\mathrm{FC}_{2}$ $\mathrm{X} \mathrm{FC}_{1}$ during fifth instar 
Table 3: Changes in the uric acid content in the dry excrement of PM X CSR 2 during fifth instar (Each value is mean of the three separate observations)

\begin{tabular}{|c|c|c|}
\hline Days & mg of uric acid/g & \%change \\
\hline 1 & $14.24 \pm 0.019$ & - \\
\hline 2 & $14.8 \pm 0.037$ & $3.723 \mathrm{NS}$ \\
\hline 3 & $15.15 \pm 0.035$ & $6.06^{*}$ \\
\hline 4 & $16.2 \pm 0.010$ & $12.09^{* *}$ \\
\hline 5 & $16.57 \pm 0.023$ & $14.06^{* *}$ \\
\hline 6 & $16.86 \pm 0.012$ & $15.53^{* *}$ \\
\hline
\end{tabular}

$\mathrm{NS}=$ Non significant

$*=$ Significant at $0.05 \%$ probability

$* *=$ Highly significant at $0.05 \%$ probability

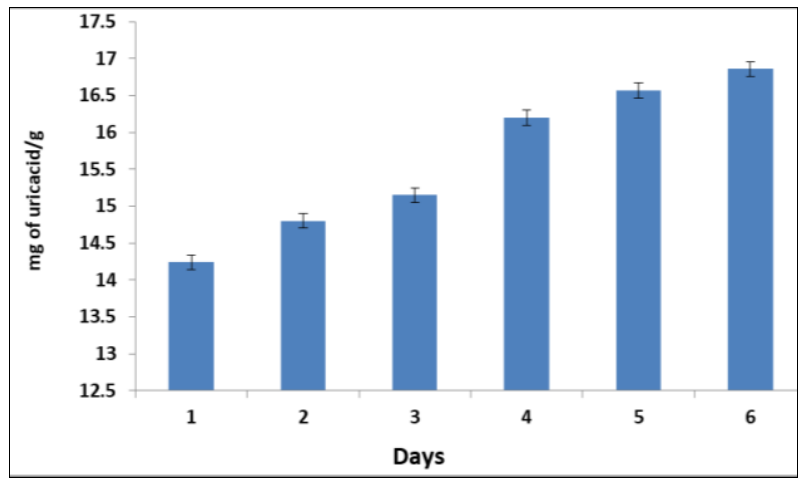

Fig 3: Changes in the uric acid content of dry excrement of PM X $\mathrm{CSR}_{2}$ during fifth instar

Table 4: Changes in the uric acid content in the dry excrement of $\mathrm{FC}_{2} \mathrm{X} \mathrm{FC}$ during fifth instar (Each value is mean of the three separate observations)

\begin{tabular}{|c|c|c|}
\hline Days & mg of uric acid/g & \%change \\
\hline 1 & $15.14 \pm 0.053$ & - \\
\hline 2 & $15.33 \pm 0.016$ & $1.23 \mathrm{NS}$ \\
\hline 3 & $15.45 \pm 0.013$ & $2.006 \mathrm{NS}$ \\
\hline 4 & $16.1 \pm 0.022$ & $5.96^{*}$ \\
\hline 5 & $16.36 \pm 0.043$ & $7.45^{*}$ \\
\hline 6 & $16.41 \pm 0.020$ & $7.73^{*}$ \\
\hline 7 & $17.51 \pm 0.033$ & $13.53^{* *}$ \\
\hline
\end{tabular}

NS =Non significant

$*=$ Significant at $0.05 \%$ probability

** = Highly significant at $0.05 \%$ probability

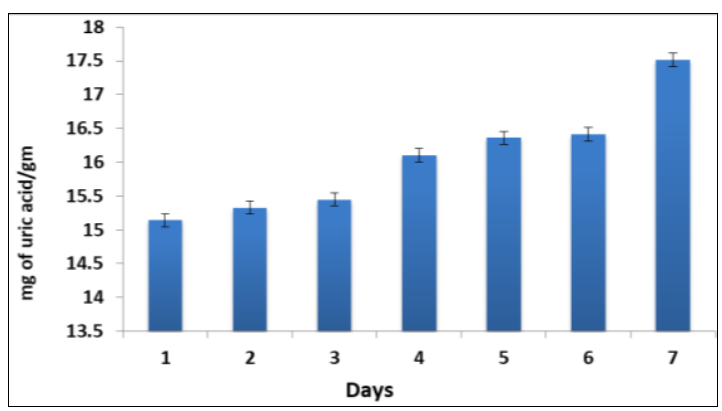

Fig 4: Changes in the uric acid content of dry excrement of $\mathrm{FC}_{2} \mathrm{X}$ $\mathrm{FC}_{1}$ during fifth instar

Table 5: Day wise change in uric acid content of the malpighian tubules and dry excrement of PM X CSR 2 during fifth instar (Each value is mean of three separate observations)

\begin{tabular}{|c|c|c|c|}
\hline Days & Malpighian tubules & Excrement & \%change \\
\hline 1 & $10.84 \pm 0.001$ & $14.24 \pm 0.019$ & 23.876 \\
\hline 2 & $10.89 \pm 0.003$ & $14.8 \pm 0.037$ & 26.418 \\
\hline 3 & $10.90 \pm 0.002$ & $15.15 \pm 0.035$ & 28.05 \\
\hline 4 & $10.92 \pm 0.002$ & $16.2 \pm 0.010$ & 32.592 \\
\hline 5 & $11.07 \pm 0.005$ & $16.57 \pm 0.023$ & 33.192 \\
\hline 6 & $11.10 \pm 0.001$ & $16.86 \pm 0.012$ & 34.163 \\
\hline
\end{tabular}

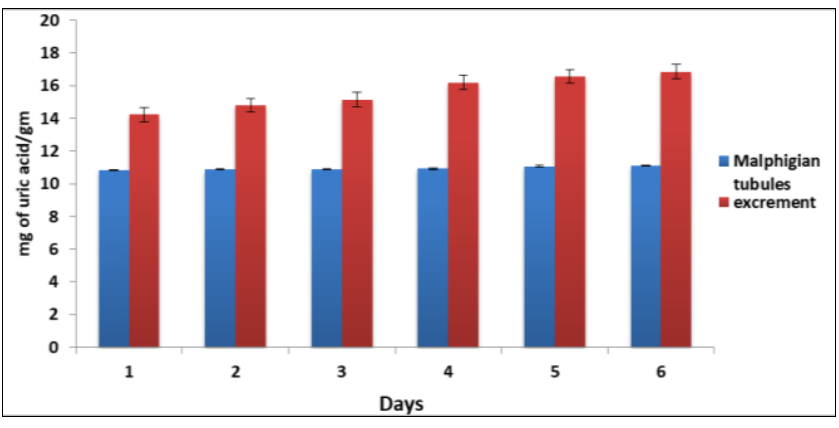

Fig 5: Day wise changes in uric acid content in Malpighian tubules and dry excrement of PM X CSR 2 during fifth instar.

Table 6: Day wise change in uric acid content in the malpighian tubules and dry excrement of $\mathrm{FC}_{2} \mathrm{X} \mathrm{FC}_{1}$ during fifth instar (Each value is mean of three separate observations)

\begin{tabular}{|c|c|c|c|}
\hline Days & Malpighiantubules & Excrement & \%change \\
\hline 1 & $10.84 \pm 0.001$ & $15.14 \pm 0.053$ & 28.401 \\
\hline 2 & $10.85 \pm 0.002$ & $15.33 \pm 0.016$ & 29.223 \\
\hline 3 & $10.86 \pm 0.003$ & $15.45 \pm 0.013$ & 29.708 \\
\hline 4 & $10.93 \pm 0.001$ & $16.1 \pm 0.022$ & 32.111 \\
\hline 5 & $10.95 \pm 0.003$ & $16.36 \pm 0.043$ & 33.068 \\
\hline 6 & $10.96 \pm 0.003$ & $16.41 \pm 0.020$ & 33.211 \\
\hline 7 & $10.97 \pm 0.002$ & $17.51 \pm 0.033$ & 37.350 \\
\hline
\end{tabular}

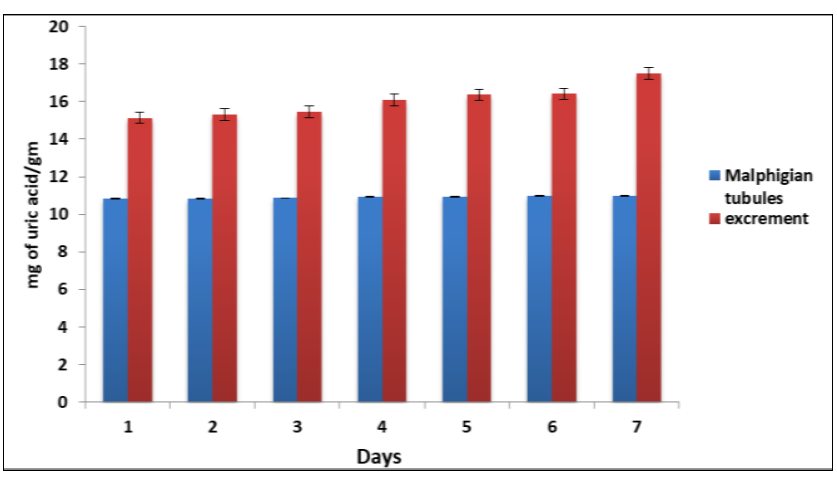

Fig 6: Day wise changes in uric acid content in the dry excrement and malpighian tubules of $\mathrm{FC}_{2} \mathrm{X} \mathrm{FC}_{1}$ during fifth instar.

Table 7: Economic traits of the $\mathrm{PM} \mathrm{XCSR}_{2}$ and $\mathrm{FC}_{2} \mathrm{X}$ FC 1 hybrids.

\begin{tabular}{|c|c|c|c|c|c|c|c|}
\hline $\begin{array}{c}\text { Economic } \\
\text { traits } \\
\text { Hybrids }\end{array}$ & $\begin{array}{c}\text { Cocoon } \\
\text { weight } \\
(\mathbf{g})\end{array}$ & $\begin{array}{c}\text { Shell } \\
\text { weight } \\
(\mathbf{g})\end{array}$ & $\begin{array}{c}\text { Shell } \\
\text { ratio } \\
\mathbf{\%}\end{array}$ & $\begin{array}{c}\text { Filament } \\
\text { length } \\
(\mathbf{m})\end{array}$ & $\begin{array}{c}\text { Filament } \\
\text { weight } \\
(\mathbf{g})\end{array}$ & $\begin{array}{c}\text { Denier } \\
(\mathbf{d})\end{array}$ & $\begin{array}{c}\text { Renditta } \\
(\mathbf{k g})\end{array}$ \\
\hline PMX & 1.596 & 0.265 & 16.625 & 896.125 & 0.297 & 2.980 & 8.28 \\
CSR2 & \pm & \pm & \pm & \pm & \pm & \pm & \pm \\
& 0.051 & 0.009 & 1.112 & 49.708 & 0.007 & 0.084 & 0.390 \\
\hline FC2 X & 1.870 & 0.395 & 21.01 & 1104.33 & 0.350 & 2.851 & 5.369 \\
FC1 & \pm & \pm & \pm & \pm & \pm & \pm & \pm \\
& 0.06 & 0.002 & 0.358 & 77.67 & 0.01 & 0.06 & 0.25 \\
\hline
\end{tabular}




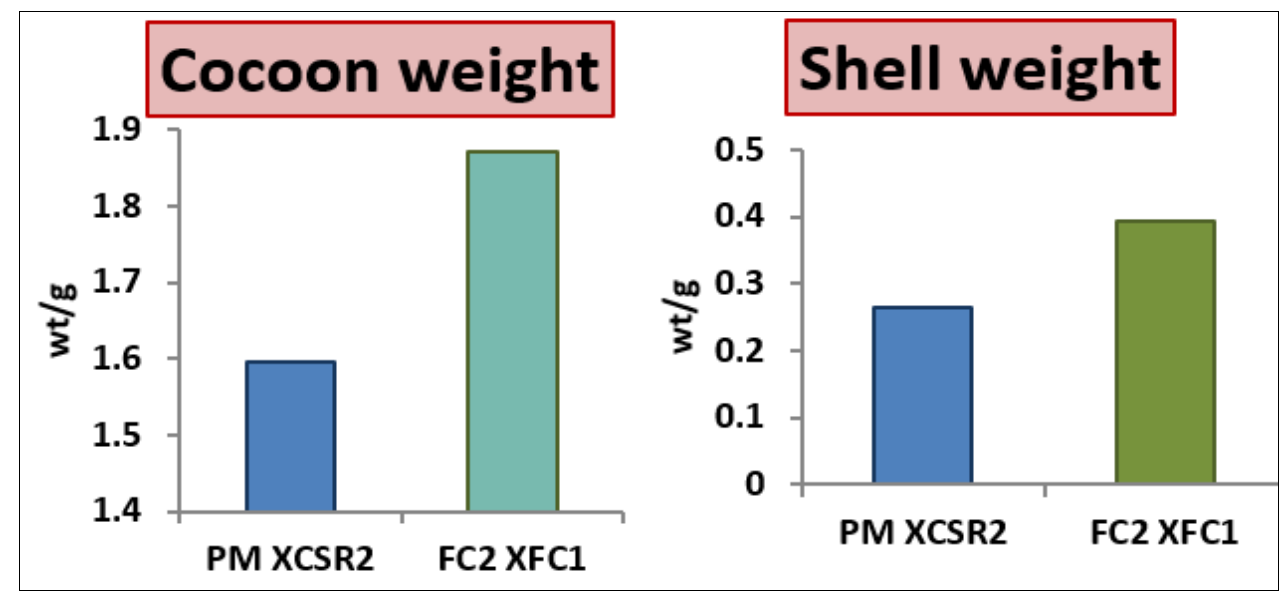

Fig 7: Cocoon weight and shell weight of $\mathrm{PM} \mathrm{X} \mathrm{CSR}_{2}$ and $\mathrm{FC}_{2} \mathrm{X} \mathrm{FC} \mathrm{F}_{1}$ silkworm hybrids
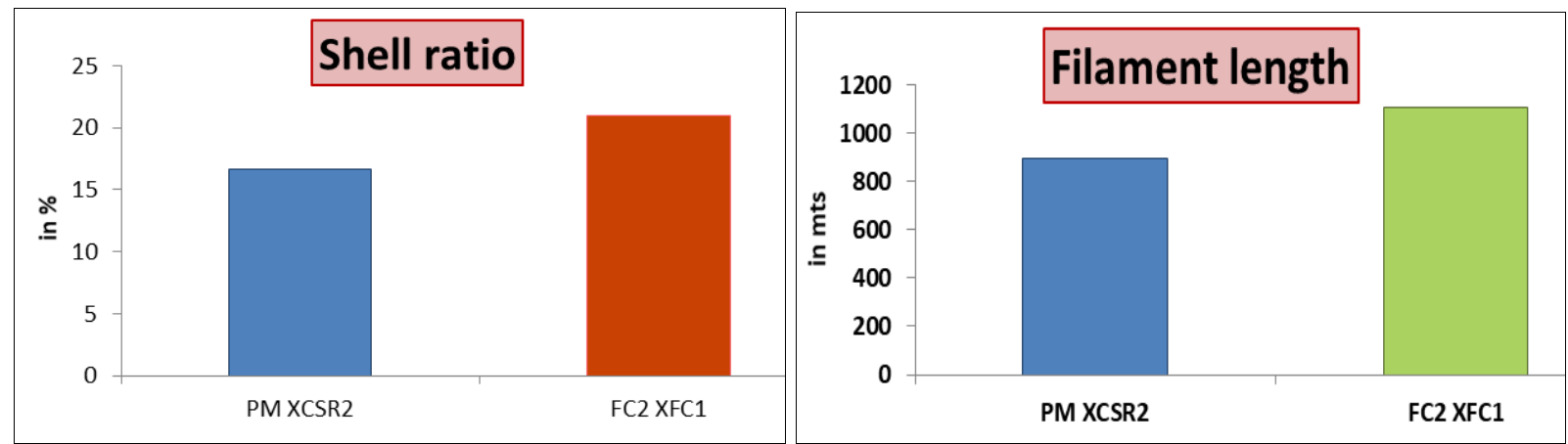

Fig 8: Shell ratio and Filament length of $\mathrm{PM} \mathrm{X} \mathrm{CSR}_{2}$ and $\mathrm{FC}_{2} \mathrm{X} \mathrm{FC}_{1}$ silkworm hybrids

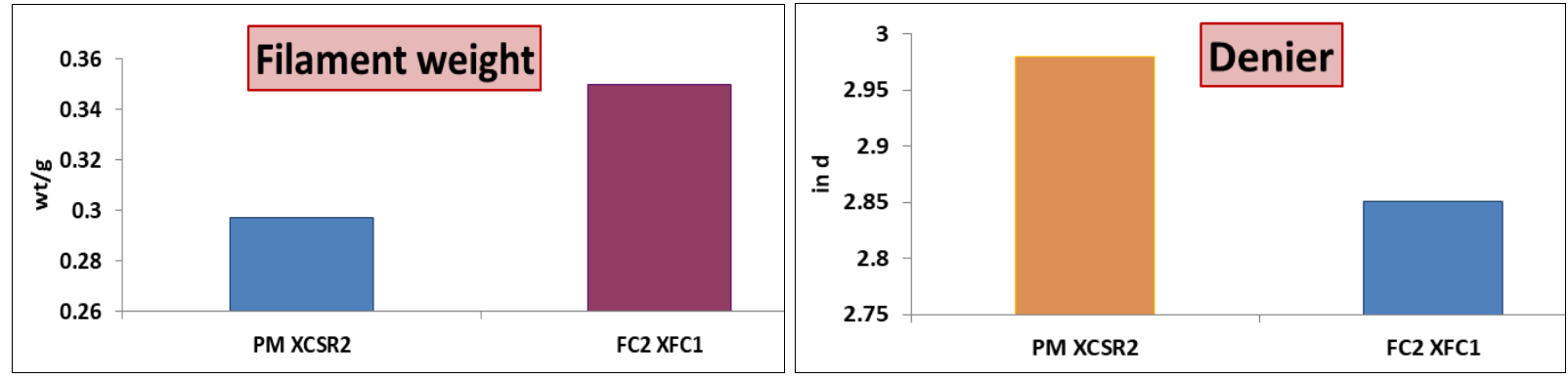

Fig 9: Filament weight and filament denier of $\mathrm{PM} \mathrm{X} \mathrm{CSR}_{2}$ and $\mathrm{FC}_{2} \mathrm{X} \mathrm{FC}$ silkworm hybrids

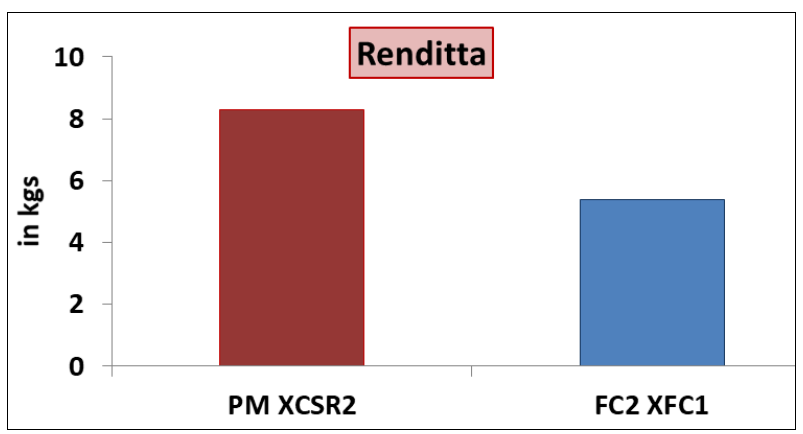

Fig 10: Renditta of $\mathrm{PM} X \mathrm{CSR}_{2}$ and $\mathrm{FC}_{2} \mathrm{X} \mathrm{FC}$ silkworm hybrids

\section{Conclusion}

The silkworm, Bombyx mori L. is cold blooded lepidopteron insect mainly responsible for the synthesis and release of uric acid as nitrogenous waste product. In the present investigations, the amounts of nitrogenous uric acid are found to be determined both in malpighian tubule and dry litter during fifth instar. The $\mathrm{PM} \mathrm{X} \mathrm{CSR}_{2}$ and $\mathrm{FC}_{2} \mathrm{X} \mathrm{FC}_{1}$ silkworm hybrids revealed as positive respond and consistent increase in the level of production of uric acid. The pattern of formation of uric acid in malpighian tubules of both the hybrids exhibits consistent level of increase in all the days of fifth instar; however, the quantum of uric acid is relatively more on the last two days of fifth instar silkworm larvae. The level of changes in uric acid content is comparatively higher than the Malpighian tubules in all the days of $\mathrm{V}$ instar silkworm of both the hybrids. The expression and manifestation of both the quantitative and qualitative traits of $\mathrm{PM} \times \mathrm{CSR}_{2}$ and $\mathrm{FC}_{2} \mathrm{X} \mathrm{FC}_{1}$ were recorded. The cocoon characters namely, cocoon weight, shell weight and shell ratio was evaluated. The cocoon characters of $\mathrm{FC}_{2} \mathrm{X} \mathrm{FC}$ hybrid showed better in performance in the expression and manifestation compare to $\mathrm{PM} \times \mathrm{CSR}_{2}$ hybrid in cocoon weight, shell weight and shell ratio pre-monsoon. The filament length and filament weight are the qualitative parameters also reflected on par with the cocoon characters. The thickness of the filament is predetermined and reflected the quality of the silk. In $\mathrm{FC}_{2} \mathrm{X} \mathrm{FC}_{1}$ the denier is lesser than the PM X $\mathrm{CSR}_{2}$ which shows the denier is almost doubled. Finally, the quantum of cocoons required to produce one $\mathrm{kg}$ of raw silk is of almost $5.36 \mathrm{~kg}$ whereas, the PM X CSR 2 showed $8.28 \mathrm{~kg}$ for the production of one $\mathrm{kg}$ of raw silk. In the 
present empirical analysis in relation to the uric acid content in dry excrement and malpighian tubules during fifth instar are carried out to understand the day to day changes in the chief nitrogenous waste product of the silkworm, Bombyx mori L.

\section{Acknowledgement}

The authors greatly acknowledge to Department of Studies in Sericulture, University of Mysore, Manasagangothri, Mysore570006 for providing facilities to conduct research.

\section{References}

1. Alexandria A, Stanchion N: Observations on the variation of amino acid content in non-diapause and diapaused chrysalides of Phylosamia ricini in relation to cocoon formation season. Zootec. 1981; 24:85-88.

2. Bharathi D. Effect of Prostaglandin P2 (alpha) on the excretory pattern of Silkworm, Bombyxmori L. J Sericulture. 1993; 1:56-58.

3. Bhattacharya AK, Waldbhaurr GP. Quantitative determination of Uric acid in insect faeces by lithium carbonate extraction and enzymatic spectrophotomtric method. Ann. Ent. Soc. Am.1969; 2:3-7.

4. Brown H. Biochemical analysis. J Biol. Chem. 1945; 158:601.

5. Cochran DG. Excretion in insects; in Insect biochemistry and/unction (eds) DJ Candy and BA. Kilby (London: Chapman and Hall), 1975, 177-281.

6. Corrigan JJ. Nitrogenous metabolism in insects. Acad. Press. 1970; 1:388-488.

7. Craig R. The physiology of excretion in insects. Ann. Rev. Entmol. 1960; 5:53.

8. Dhinaker GM, Bhasker M, Rajashekar R, Govindappa S. Changes in the excretory pattern during winter at different stages of the larvae of silkworm, Bombyxmori L. Ind. J Comp. Anim. Physiol. 1990; 8:59-62.

9. Florey E. Excretion in insects. Energytier and functional principles. J Exp. Biol. 1982; 99:417-424.

10. Heller J, Jezeweska MM. The synthesis of uric acid in the Chinese tusser moth (A. Pernyi). Bull. Acad. Pol. Sci. Cl. II, Seri. Sci. Biol. 1959; 7:1-4.

11. Karowe DN, Martin, Michael M. The effects of quantity and quality of diet nitrogen on the growth, efficiency of food utilization, nitrogen budget, and metabolic rate of fifth-instar Spodoptera eridania larvae (Lepidoptera: Noctuidae). Journal of Insect Physiology. 1989; 35(9):699-708.

12. Leifert H. Study of excretory substances in the larvae and pupae of Antheraeapernyei (Lepidoptera). Jb. Abl. Allg. Zool. Physiol. 1935; 55:131-190.

13. Mitlin N, Mauldin JK. Uric acid in nitrogen metabolism of the boll weevil: A preliminary study. Ann. ent. Soc. Am. 1966; 59: 651-653.

14. Oser BL. Blood analysis. Hawk's physiological chemistry. Tata Mc. Graw Hill Publishing Co. Ltd., Bombay, 1965, 1047-1048.

15. Prosser CL, Brown FA. Comparative animal physiology. 2 nd Edn. WB. Saunders, 1965, 75.

16. Rajan RK, Himantharaj MT. A Text Book on Silkworm Rearing Technology. Published by Central Silk Board, 2005.

17. Razet P. Recherches sur l'uricolyse chez les insectes; Bull. Soc. Sci. Britaqne. 1961; 36:1-206.

18. Sailaja K, Pushpa Rani P, Bharathi D, Murali Mohan P.
Effect of cobalt on the nitrogenous end products of silkworm, Bombyxmori L. Environ. Ecol. 1997; 15:151153.

19. Shamitha G, Purushotham Rao A. Studies on excretory products of Outdoor and total indoor reared tasar silkworm, Antheraeamylitta Drury. J Exp. Zool. 2001; 4:115-119.

20. Shamitha G. A Purushotham Rao. Estimation of glycogen and trehalose of outdoor and total indoor reared tasar silkworm, Antheraeamylitta Drury. Ind. J Comp. Anim. Physiol. 2000; 18:40-43.

21. Shamitha G. A Purushotham Rao. Estimation of protein and lipid content in tasar silkworm, Antheraea mylitta Drury (Andhra local ecorace). J A.P. Acad. Sci. 2005; 9:325-331.

22. Siddiqui A, Babulal A, Sharma AK, Chauhan TPS, Khatri RK. Breeding park for tasar silkworm in uttaranchal: A feasibility. Ind. Silk. 2006; 45:12-15.

23. Timmermann SE, Zangerl AR, Berenbaum MR. Ascorbic and Uric Acid Responses to Xanthotoxin Ingestion in a Generalist and a Specialist Caterpillar. Archives of Insect Biochemistry and Physiology. 1999; 42:26-36.

24. Wigglesworth V.B. The Principles of Insect Physiology, London Methuen, England, 1950.

25. Wigglesworth, V.B. The Principles of Insect Physiology. 7th Edn. Chapman and Hall, London, 1965.

26. Yamada A, Y Kato: Amino acid composition and characteristic chromophore of a blue bili protein in larval haemolymph of A. Yamamai. Wild Silk moths. 1991; 55:196-202. 